\section{Keeping them up in the air}

\section{Thomas A. McMahon}

Bird Flight Performance: A Practical Calculation Manual. By C. J. Pennycuick. Clarendon: 1989. Pp.153. £25, \$49.95.

THE subtitle says this book is a "practical calculation manual". Right away, the prospective reader wonders what that could be. Manuals are generally not much fun for off-duty reading. There are many people who might like to read an informative book about bird flight, but few who need to make calculations. The prospective reader wonders if this is a book or a computer manual, and if it's a manual, shouldn't it be someone else's job to read it?

The first chapter doesn't make the question go away. In the very first paragraph, the author launches into a discourse about how millilitres of oxygen and grams of fat are not units of energy. He reveals here, as in other places in the book, that he is on a mission to set some of his colleagues straight about the right way of doing certain things. On p.11, for example, he draws the right and wrong methods of tracing a wing to find its area. On p.8 he says that some collections of data in the literature have to be treated with caution "because ornithologists have proved surprisingly creative in inventing wrong ways to make even the simplest measurements".

Not until the reader is well into the book does it dawn, like a bright light switching on, that this volume - manual or not represents a beautiful and original achievement. From then on, it doesn't matter whether it is a book, a manual or a computer program (actually, it is all three). What matters is that Pennycuick has invented something here; a way of exploring a complex biological subject through first-hand revelations using a calculation model.

It is a very successful invention. Books are good tools for self-education, but Pennycuick obviously believes there are better ways to learn. The best way is not to be told the answer but to be given the opportunity to discover it for oneself. Pennycuick's invention is not at all like computer-aided instruction, where the program asks the user a question and then scolds and corrects when it thinks the answer is wrong. Using the programs provided here, the user is responsible for formulating a scientific question. An example (p.88) might be: why do birds of intermediate size use a mode of intermittently powered flight (bounding) in which the wings are folded against the body during the non-flapping phase? The user

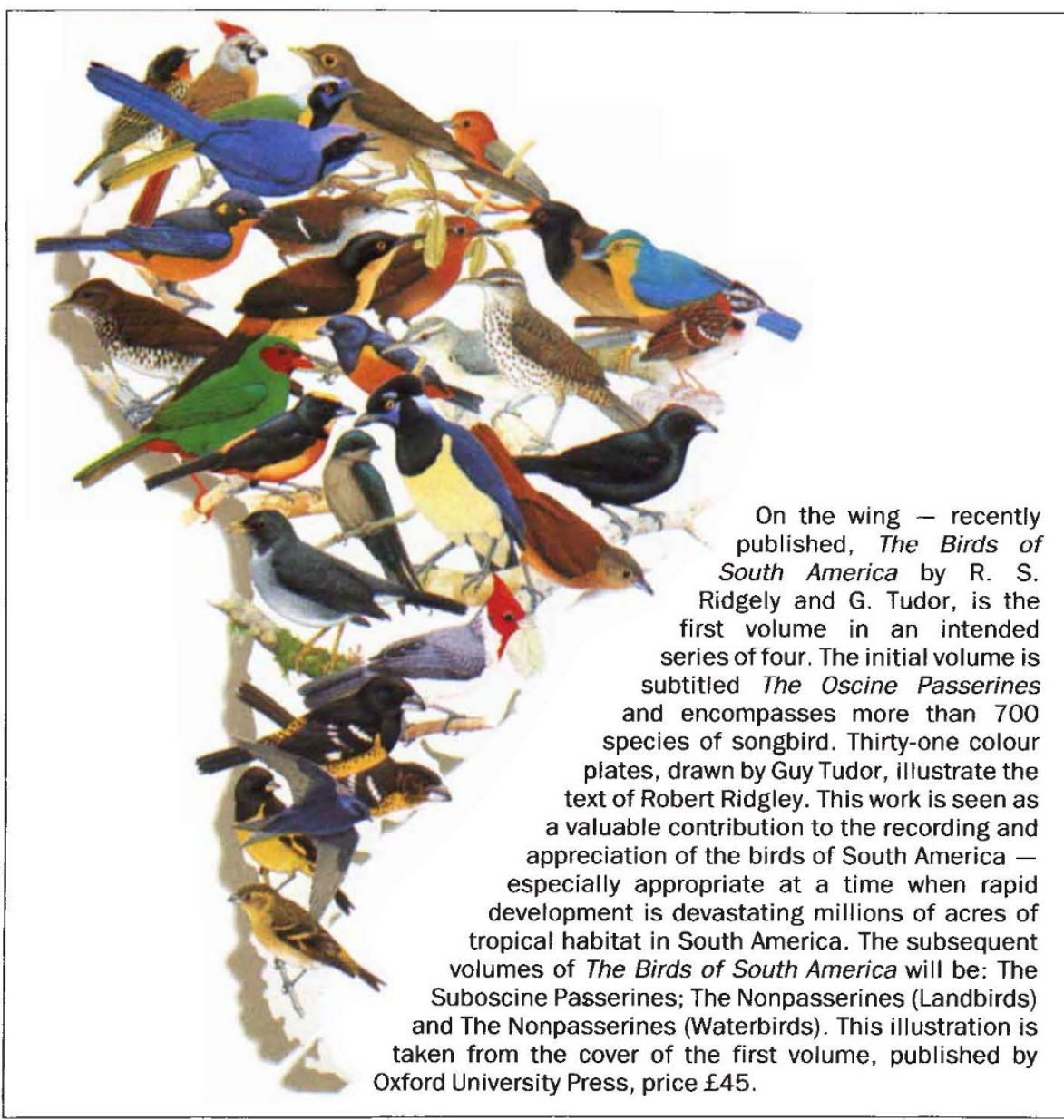

can work out answers to such questions by obtaining measurements, not on animals, but from a calculated simulation of what the animal would do in the presumed situation. Most of the book concerns explanations of how the programs arrive at their answers. Pennycuick provides brief discussions of the physical and biological principles behind the calculations, emphasizing throughout the importance of selecting and configuring the program for the task at hand and staying within the limitations inherent in the program's assumptions. He has made it straightforward to change the assumptions when necessary, as, for example, when the air density is lower because the bird is flying at altitude.

The book is full of fresh insights I have never seen published. I liked the very simple and clear discussion of Reynolds number on p.43, where the author points out that the ratio of inertial force to viscous force acting on the air in a little cube flowing around an obstruction grows larger if you scale the whole drawing up because the ratio of the cube's mass to its surface area increases. On p.50 I was told that a snow goose body in a wind tunnel has 15 per cent less drag when the feathers are coated by hair spray. In a living bird, the feathers can be controlled by pteromotor muscles, presumably giving some of the same effect. On p.62, there is a diagram of the concertina wake, in which the bird flexes and shortens its wings on the upstroke while flapping, so that no transverse vortices are shed, and consequently less energy is required than would be the case for flapping wings of fixed span.

A particularly nice use of the programs included with the book is discussed on p.107, where the author asks why small birds don't take advantage of the energy in the atmosphere and soar as large birds do. He shows how his programs can produce a telling calculation comparing a 5.5kilogram crane to a 17.4-gram ovenbird, assuming both birds have 1 metre per second thermals to soar in. Whereas the crane requires only 15 per cent as much energy per kilometre to migrate using thermals as to flap along in still air, the little ovenbird uses 6 per cent more energy per kilometre riding the thermals. The reason the small bird comes out so badly is that its basal metabolism is a much larger fraction of the total energy requirement. Because the small bird spends almost three times as long using thermals as it would flying direct, the extra time results in an extra cost for basal metabolism that overwhelms the energy savings that would be available from gliding instead of flapping.

Thomas A. McMahon is in the Division of Applied Sciences at Hanvard University, Cambridge, Massachusetts 02138, USA. 